\title{
Creating Added Value with a Waste: Methylation of Amines with $\mathrm{CO}_{2}$ and $\mathrm{H}_{2}$ **
}

\author{
Anis Tlili, Xavier Frogneux, Enguerrand Blondiaux, and Thibault Cantat*
}

amines $\cdot$ catalysis $\cdot \mathrm{CO}_{2} \cdot$ hydrogen .

sustainable chemistry

$\boldsymbol{T}_{\text {he }}$ alternative to $\mathrm{CO}_{2}$ storage for cutting the emissions of this greenhouse gas, while creating added value that can compensate for the energetic and economic costs of its capture. In this respect, the reduction of $\mathrm{CO}_{2}$ to fuels has the potential to mitigate meaningful volumes of anthropogenic $\mathrm{CO}_{2}$ emissions. Nonetheless, the current technologies cannot compete with the low cost of fossil fuels (hydrocarbons, coal, and gas). In fact, $\mathrm{CO}_{2}$ utilization is limited today to applications outside of the fuel sector, such as consumer goods (food preservatives, drinks, etc.), enhanced oil recovery (EOR) technologies, and the production of chemicals. ${ }^{[1]}$ Among them, the conversion of $\mathrm{CO}_{2}$ to chemicals represents about $70 \%$ of the 220 megatonnes of $\mathrm{CO}_{2}$ utilized annually. This segment is dominated by a handful of processes, namely the Bosch-Meiser process for the production of urea from $\mathrm{CO}_{2}$ and ammonia, the KolbeSchmitt synthesis of salicylic acid (from $\mathrm{CO}_{2}$ and phenol), and the transformation of $\mathrm{CO}_{2}$ to carbonates. ${ }^{[1]}$ Interestingly, these reactions result in the functionalization of $\mathrm{CO}_{2}$ without significantly reducing the carbon oxidation state. Indeed, $\mathrm{CO}_{2}$ reduction, using renewable carbon-free reductants and abundant noble-metal-free catalysts, remains a challenge for the design of novel utilization technologies. $\mathrm{CO}_{2}$ is therefore an attractive carbon feedstock as it is cheap, renewable, and nontoxic and its transformation could contribute to achieving sustainability in the chemical industry. It should be noted, however, that its conversion to chemicals will not reduce significantly $\mathrm{CO}_{2}$ emissions as this application scales to a maximum of $5 \%$ of the 30 gigatonnes of $\mathrm{CO}_{2}$ released every year by human activities. The main advantage of $\mathrm{CO}_{2}$ conversion to chemicals is the concomitant creation of added value which can circumvent the cost associated with $\mathrm{CO}_{2}$ capture and transformation. As an example, the six-electron reduction of $\mathrm{CO}_{2}$ to methanol must compete with the petrochemical production of $\mathrm{MeOH}$, which sets its market

[*] Dr. A. Tlili, X. Frogneux, E. Blondiaux, Dr. T. Cantat CEA, IRAMIS, SIS2M, CNRS UMR 3299

91191 Gif-sur-Yvette (France)

E-mail: thibault.cantat@cea.fr

Homepage: http://iramis.cea.fr/Pisp/thibault.cantat/index.html

$[\cdots *$ This work was supported financially by the CEA, CNRS, ADEME, the CHARMMMAT Laboratory of Excellence, and the European Research Council (ERC Starting Grant Agreement no.336467). T.C. thanks the Fondation Louis D.-Institut de France for its generous support. value to $410 €$ per tonne. In contrast, the market value of methylamines, which are platform chemicals such as $\mathrm{MeNH}_{2}$, $\mathrm{Me}_{2} \mathrm{NH}$, and $\mathrm{Me}_{3} \mathrm{~N}$, exceeds $4000 €$ per tonne. The reduction of $\mathrm{CO}_{2}$ to methylamines could therefore offer viable technologies for the transformation of $\mathrm{CO}_{2}$. Yet, this reaction remained unknown ... until 2013!

Bulk methylamines are currently produced from $\mathrm{NH}_{3} /$ $\mathrm{CH}_{3} \mathrm{OH}$ gas mixtures over heterogeneous dehydration catalysts. ${ }^{[2]}$ Methylation methodologies in fine chemicals manufacture rely on the use of formaldehyde in the presence of a reductant for the formation of $\mathrm{N}-\mathrm{CH}_{3}$ units and, in the laboratory, hazardous alkylating agents such as methyl iodide, dimethyl sulfate, and dimethyl carbonate are preferred (Scheme 1). ${ }^{[2]}$ Utilizing $\mathrm{CO}_{2}$ for the methylation of $\mathrm{N}-\mathrm{H}$

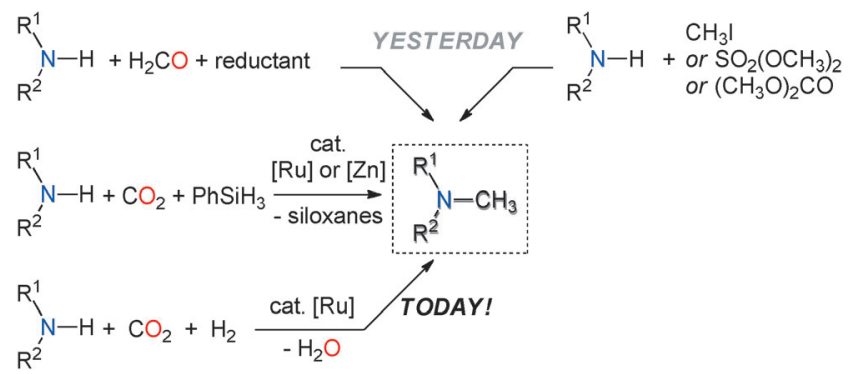

Scheme 1. Strategies for the methylation of $\mathrm{N}-\mathrm{H}$ bonds.

bonds requires the use of a mild reductant and an efficient catalyst able to promote the reduction of $\mathrm{CO}_{2}$ and facilitate the formation of a $\mathrm{C}-\mathrm{N}$ bond. This barrier was overcome in early 2013 when two research groups independently reported two catalytic systems able to convert $\mathrm{CO}_{2}$ to methylamines, in the presence of amines and hydrosilanes $\left(\mathrm{PhSiH}_{3}\right)$. A discrete $\mathrm{N}$-heterocyclic carbene/Zn complex exhibited good activity for the formation of methylamines from both aliphatic and aromatic amines and $\mathrm{CO}_{2} \cdot{ }^{[3]}$ Shortly afterwards, the group of Beller developed a $\mathrm{Ru} /$ phosphine system that enables the methylation of a large variety of anilines as well as aliphatic amines, albeit under a higher $\mathrm{CO}_{2}$ pressure (30 bar). ${ }^{[4]}$ Nonetheless, these methodologies are limited by the availability of the hydrosilane reagent and owing to the formation of siloxane by-products a subsequent workup step is required to recover the methylamine product. 
Hydrogen is a desirable reductant for the large-scale utilization of $\mathrm{CO}_{2}$ because it has a mild reduction potential suitable for the reduction of $\mathrm{CO}_{2}$, and its oxidized form is benign $\mathrm{H}_{2} \mathrm{O}$. Additionally, current efforts devoted to the (photo)electroreduction of water may offer cost-efficient and carbon-free sources of $\mathrm{H}_{2}$ in the near future. In this context, a breakthrough in the methylation of amines using $\mathrm{CO}_{2}$ and $\mathrm{H}_{2}$ has been reported very recently by the group of Klankermayer and Leitner ${ }^{[5]}$ and the group of Beller. ${ }^{[6]}$ Capitalizing on previous mechanistic and experimental work, ${ }^{[7]}$ Klankermayer et al. demonstrated the efficient conversion of $\mathrm{CO}_{2}$ to $N, N^{\prime}$-dimethylaniline, using an optimized ruthenium(II) complex supported by a triphosphine ligand (triphos) in the presence of $\mathrm{H}_{2}$ and $\mathrm{N}$-methylaniline. In contrast, Beller et al. have generated an active [Ru(triphos)] catalyst in situ from $\left[\mathrm{Ru}(\mathrm{acac})_{3}\right]$ and triphos. In both catalytic systems, the use of a catalytic amount of acids (MSA = methanesulfonic acid or $\mathrm{HNTf}_{2}=$ trifluoromethanesulfonimide) is crucial for the generation of the $\mathrm{Ru}-\mathrm{H}$ active species. ${ }^{[7]}$ The two methodologies require similar pressures $\left(\mathrm{H}_{2} / \mathrm{CO}_{2}\right.$ : $60 / 20$ bar) and temperatures $\left(140-150^{\circ} \mathrm{C}\right)$, and they result in the respective mono- or bis-methylation of primary and secondary anilines in very good to excellent yields (Scheme 2). In fact, the two catalytic systems share notable

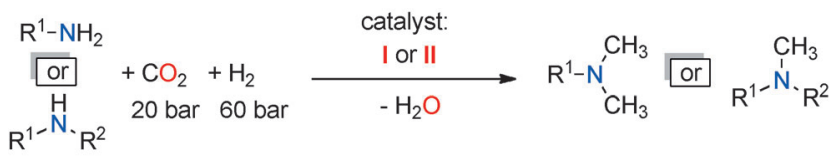

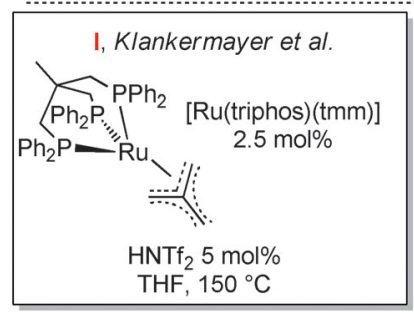

20 examples up to $94 \%$ yield

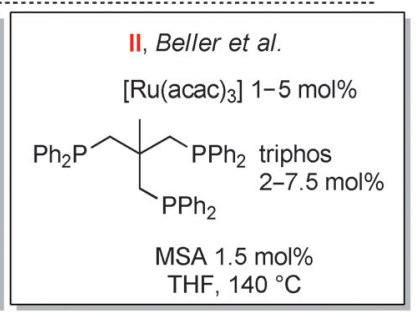

33 examples up to $99 \%$ yield
Scheme 2. Methylation of amines with $\mathrm{CO}_{2}$ and $\mathrm{H}_{2}$.

similarities which likely originate in their conception. Indeed, the methylation of an amine with $\mathrm{CO}_{2}$ requires a catalyst able to promote both the six-electron reduction of $\mathrm{CO}_{2}$ and the formation of a $\mathrm{C}-\mathrm{N}$ bond. A viable route for this sequence involves first the formylation of the $\mathrm{N}-\mathrm{H}$ bond and the subsequent reduction of the formamide intermediate. ${ }^{[3]} \mathrm{Ru}^{\mathrm{II}}-$ phosphine complexes are proven efficient catalysts for the hydrogenation of $\mathrm{CO}_{2}$ to methanol, ${ }^{[\mathrm{a}]}$ the formylation of amines with $\mathrm{CO}_{2}$ and $\mathrm{H}_{2},{ }^{[8 b]}$ and the hydrogenation of amides, ${ }^{[8-\mathrm{c}]}$ and they can now be employed to promote the synthesis of methylamines from $\mathrm{CO}_{2} / \mathrm{H}_{2}$ /amine mixtures.

Mechanistically, both research groups conclude that a sequential formylation/amide reduction is indeed the most favorable route for the methylation reaction, as the formation of formamide intermediates was clearly demonstrated. Focusing on supplementary aspects of this novel transformation, the two groups have explored its scope, potential, and limitations. Aliphatic amines appear to be the least reactive substrates, presumably because the reduction of the corresponding formamide intermediate is more difficult in the absence of an aromatic substituent. However, Beller's group found that replacing the acid promoter with $\mathrm{LiCl}$ salt and increasing the catalyst loadings resulted in the quantitative bismethylation of aliphatic primary amines such as benzylamine. In parallel, Klankermayer et al. took advantage of the catalytic activity of the $\left[\mathrm{Ru}(\right.$ triphos $\left.)(\mathrm{tmm}) / \mathrm{HNTf}_{2}\right](\mathrm{tmm}=$ trimethylene methane) system for the hydrogenation of amides to promote the sequential hydrogenation/N-methylation of acetanilides, as an entry to unsymmetric methyl/alkyl anilines. The chemoselectivity of the reaction was investigated and the monomethylation of diamines shows promising selectivity. Despite the reductive conditions, the methylation of primary anilines is tolerant to ether, ester, and hydroxy groups and carbon-halogen functionalities. Whereas the group of Klankermayer and Leitner observed that the methylation of indole is accompanied by hydrogenation of the $\mathrm{C}=\mathrm{C}$ double bond, Beller's system enables the methylation of nortriptyline, leaving the trisubstituted olefin untouched. This latter reaction was utilized for the synthesis of ${ }^{13} \mathrm{C}$-labeled amitriptyline from ${ }^{13} \mathrm{CO}_{2}$. The utilization of this groundbreaking technology for the production of platform methylamines, such as $\mathrm{MeNH}_{2}$ and $\mathrm{Me}_{2} \mathrm{NH}$, might benefit from a heterogeneous catalytic system. Surprisingly, the group of Shi reported very recently a $\mathrm{CuAlO}_{x}$ catalyst that facilitates the methylation of amines with $\mathrm{CO}_{2}$ and $\mathrm{H}_{2}$, albeit with high catalyst loadings. Primary and secondary aromatic and aliphatic amines as well as nitriles and nitroarenes were converted to methylamines at elevated temperatures (up to $\left.170^{\circ} \mathrm{C}\right)$ and pressures $\left(\mathrm{H}_{2} / \mathrm{CO}_{2}: 60-70 / 30 \mathrm{bar}\right) .{ }^{[9]}$

In conclusion, the systems highlighted herein were used for the first conversion of $\mathrm{CO}_{2}$ to methylamines with $\mathrm{H}_{2}$. These results will undoubtedly foster novel efforts to increase the activity, stability, and selectivity of the catalytic systems and bring this methodology to the plant. In particular, tolerance to reducible functional groups such as carboxylic acid derivatives, aldehydes, and ketones would be desirable. Although clearly challenging, extending this strategy to the selective methylation of ammonia could provide a sustainable route to basic methylamines in industry.

Received: November 28, 2013

Published online: February 12, 2014

[1] a) M. Aresta, Carbon Dioxide as Chemical Feedstock, WileyVCH, Weinheim, 2010; b) K. Huang, C. L. Sun, Z. J. Shi, Chem. Soc. Rev. 2011, 40, 2435; c) T. Sakakura, J. C. Choi, H. Yasuda, Chem. Rev. 2007, 107, 2365.

[2] a) M. F. Ali, B. M. ElAli, J. G. Speight, Handbook of Industrial Chemistry-Organic Chemicals, McGraw-Hill, New York, 2005; b) H.-J. Arpe, S. Hawkins, Industrial Organic Chemistry, WileyVCH, Weinheim, 1997.

[3] O. Jacquet, X. Frogneux, C. D. N. Gomes, T. Cantat, Chem. Sci. 2013, 4, 2127.

[4] Y. Li, X. Fang, K. Junge, M. Beller, Angew. Chem. 2013, 125, 9747; Angew. Chem. Int. Ed. 2013, 52, 9568.

[5] K. Beydoun, T. vom Stein, J. Klankermayer, W. Leitner, Angew. Chem. 2013, 125, 9733; Angew. Chem. Int. Ed. 2013, 52, 9554. 
[6] Y. Li, I. Sorribes, T. Yan, K. Junge, M. Beller, Angew. Chem. 2013, 125, 12378; Angew. Chem. Int. Ed. 2013, 52, 12156.

[7] a) F. M. A. Geilen, B. Engendahl, A. Harwardt, W. Marquardt, J. Klankermayer, W. Leitner, Angew. Chem. 2010, 122, 5642; Angew. Chem. Int. Ed. 2010, 49, 5510; b) F. M. Geilen, B. Engendahl, M. Holscher, J. Klankermayer, W. Leitner, J. Am. Chem. Soc. 2011, 133, 14349 .

[8] a) S. Wesselbaum, T. vom Stein, J. Klankermayer, W. Leitner, Angew. Chem. 2012, 124, 7617; Angew. Chem. Int. Ed. 2012, 51,
7499; b) P. G. Jessop, Y. Hsiao, T. Ikariya, R. Noyori, J. Am. Chem. Soc. 1994, 116, 8851; c) A. A. Núñez Magro, G. R. Estham, D. J. Cole-Hamilton, Chem. Commun. 2007, 3154; d) D. L. Dodds, J. Coetzee, J. Klankermayer, S. Brosinski, W. Leitner, D. J. Cole-Hamilton, Chem. Commun. 2007, 3154; published addition (November 2011); e) J. Coetzee, D. L. Dodds, J. Klankermayer, S. Brosinski, W. Leitner, A. M. Z. Slawin, D. J. ColeHamilton, Chem. Eur. J. 2013, 19, 11039.

[9] X. Cui, X. Dai, Y. Zhang, Y. Deng, F. Shi, Chem. Sci. 2014, 5, 649. 